\title{
ABO BLOOD GROUP AND THE RISK OF LUNG CANCER IN GREEK ADULTS: A CASE - CONTROL STUDY
}

\author{
N.A. Chrysanthakopoulos ${ }^{1,2, *}$, N.S. Dareioti ${ }^{3}$ \\ ${ }^{1}$ Department of Pathological Anatomy, Medical School, University of Athens, Athens 11528, Greece \\ ${ }^{2}$ Maxillofacial and Oral Surgery, 401 General Military Hospital of Athens, Athens 11527, Greece \\ 3 "Saint Andrew" Hospital of Patras, Patra PC 26 223, Greece
}

\begin{abstract}
Aim: The present study aimed to investigate any possible association between $\mathrm{ABO}$ blood groups and lung cancer. Materials and Methods: The study was conducted on 122 lung cancer patients and 1,255 matched-healthy individuals that were reviewed retrospectively. Chi-square and logistic regression models were used for statistical analysis. Results: No significant difference between lung cancer patients and the control group was recorded regarding $\mathrm{ABO}$ blood types and the risk of lung cancer ( $p=0.055$, $\mathrm{OR}=0.79,95 \% \mathrm{CI} 0.61-1.03)$. Male gender $(p=0.006, \mathrm{OR}=2.08,95 \% \mathrm{CI} 1.24-3.49)$ and smoking $(p=0.000, \mathrm{OR}=3.13$, 95\% CI 1.72-5.69) were significantly associated with the risk of lung cancer. Conclusion: No association between ABO blood types and the risk of lung cancer was observed.
\end{abstract}

Key Words: ABO blood types, lung cancer, adults, risk factor.

Lung cancer (LC) consists the main cause of cancer deaths worldwide and is the second most common type of cancer in both genders [1]. Main risk factors for LC development are smoking, exposure to environmental and workplace carcinogens, genetic factors such as advanced age, male gender, enzymes polymorphism and inherited conditions, ionizing radiation and previous lung disorders such as chronic obstructive pulmonary disease, tuberculosis, lung fibrosis and other unknown factors [2, 3].

The ABO blood groups system was discovered decades ago [4] and its antigens consist biochemical indices that are expressed in several cell types including erythrocytes, gastrointestinal cells, lung epithelial cells, mucosa cells etc. [5]. Previous reports have recorded that the $\mathrm{ABO}$ blood group was associated with several disorders and pathological conditions, including coronary heart disease [6], ischemic stroke [7] and several types of cancer [8,9], including LC [10]. However, the data on the role of ABO blood group factor in LC is limited and inconsistent as such investigations were limited by their retrospective design and small case numbers [2, 11-14].

\section{PATIENTS AND METHODS}

$122 \mathrm{LC}$ patients and 1,255 healthy individuals were assessed retrospectively. ABO blood groups distributions were similar to those for other Greek population. Individuals that were suffered from advanced LC under any form of treatment, from cancer in several locations in which smoking is considered as an obvious risk factor such as pharyngeal or larynx cancer, with lung metastases because of another primary cancer in a different location and those that were diagnosed by head-neck-thorax cancer-carcinogenesis field theory [15] - were excluded in order to avoid as much

\footnotetext{
Submitted: March 19, 2018.

*Correspondence: E-mail: nikolaos_c@hotmail.com, nchrysant@med.uoa.gr

Abbreviation used: LC - lung cancer.
}

as possible potential confounding effects on the parameters examined. The LC patients were diagnosed by histological examination whereas the controls were selected by the friendly environment of the LC patients in an attempt to control possible potential confounders such as the socioeconomic and educational level. The following variables: age, gender, smoking status (active, former/never), socioeconomic (income/ monthly $\geqslant 1,000 €$ ), educational level (graduated from University/College), history of previous pulmonary diseases, such as chronic obstructive pulmonary disease and LC family history, for the participants were estimated, whereas both groups were filled in a selfadministered questionnaire that included information regarding the mentioned aspects and data regarding their general medical history with reference to medication and several chronic systemic diseases. For each individual the mentioned variables were evaluated and coded as dichotomous variables. Chi-square and multivariate logistic regression model was carried out to investigate the possible associations. Unadjusted and adjusted odds ratio's (OR's) and 95\% confidence interval $(\mathrm{Cl})$ were also assessed. SPSS ver. 17.0. statistical package was used for the analysis and a $p$ value of $p<0.05$ was determined as significant statistically.

\section{RESULTS AND DISCUSSION}

The study sample included 680 males and $697 \mathrm{fe}-$ males ranging in age from 45 to $70+$ years old and mean age $67 \pm 4$ years. The distribution of LC patients with their histological subtype and the $A B O$ group were for squamous LC: A blood group - 42.8\%, B - 18.4\%, $A B-10.3 \%, O-28.5 \%$, for adenocarcinoma: A blood group $-32.3 \%, \mathrm{~B}-11.8 \%, \mathrm{AB}-8.8 \%, \mathrm{O}-47.1 \%$, for small cell LC: A blood group $-52.0 \%, B-8.0 \%$, $A B-8.0 \%, O-32.0 \%$ and for other subtype: A blood group $-35.7 \%, B-7.1 \%, A B-14.3 \%, O-42.9 \%$. According to univariate analysis the variables age $(p=0.000)$, educational level $(p=0.002$, OR $=0.55$, $95 \% \mathrm{Cl} 0.38-0.80)$ and smoking $(p=0.000, \mathrm{OR}=0.40$, 
95\% Cl 0.26-0.61) were found to be significantly associated with LC risk.

The primary model showed that smoking $(p=0.000$, $\mathrm{OR}=3.19,95 \% \mathrm{Cl} 1.75-5.84)$ and male gender $(p=0.013, \mathrm{OR}=1.95,95 \% \mathrm{Cl} 1.15-3.29)$ were significantly associated with $\mathrm{LC}$ risk whereas $\mathrm{ABO}$ blood type was not ( $p=0.076, \mathrm{OR}=0.77,95 \% \mathrm{Cl} 0.60-1.00)$. According to the final model, smoking $(p=0.000, \mathrm{OR}=$ $3.13,95 \% \mathrm{Cl} 1.72-5.69)$ and male gender $(p=0.006$, $\mathrm{OR}=2.08,95 \% \mathrm{Cl} 1.24-3.49$ ) were significantly associated with LC risk, whereas no significant association between $\mathrm{ABO}$ blood type and LC risk was observed $(p=0.055, \mathrm{OR}=0.79,95 \% \mathrm{Cl} 0.61-1.03)$. In the current study we investigated the possible association between ABO blood group system and the risk of LC development. Except for the known etiological and risk factors that are associated with LC development, no association was observed between those that were examined. Recent and previous reports have recorded the impact of the ABO blood types in the development of several types of cancer, including LC [9] in which it was found that blood type other than $\mathrm{O}$ was associated with the risk of LC, whereas in another study [16] no significant association was recorded.

The current study has some limitations. First, the study as a retrospective one, has some known weaknesses compared to prospective ones, such as systemic biases that concerns the sample selection and the small number of the cases, and the presence of possible confounders. However, further prospective studies are needed to clarify the mechanisms by which $A B O$ blood type may influence the LC risk. In conclusion, it was recorded that $A B O$ blood type was not associated with increased $L C$ risk.

\section{CONFLICT OF INTERESTS}

The authors have no conflict of interests to declare.

\section{REFERENCES}

1. Jemal A, Bray F, Center MM, et al. Global cancer statistics. CA Cancer J Clin 2011; 61: 69-90.
2. Dela Cruz CS, Tanoue LT, Matthay RA. Lung cancer: epidemiology, etiology, and prevention. Clin Chest Med 2011; 32: 605-44.

3. Couraud S, Zalcman G, Milleron B, et al. Lung cancer in never smokers - a review. Eur J Cancer 2012; 48: 1299-311.

4. Landsteiner K. Zur Kenntnis der antifermentativen, lytischen und agglutinierenden Wirkungen des Blutserumsund der Lymphe. Zentralbl Bakteriol 1900; 27: 357-62 (in German).

5. Graziano SL, Tatum AH, Gonchoroff NJ. Blood group antigen $\mathrm{A}$ and flow cytometric analysis in resected early stage non-small cell lung cancer. Clin Cancer Res 1997; 3: 87-93.

6. He M, Wolpin B, Rexrode K, et al. ABO blood group and risk of coronary heart disease in two prospective cohort studies. Arterioscler Thromb Vasc Biol 2012; 32: 2314-20.

7. Williams FM, Carter AM, Hysi PG, et al. Ischemic stroke is associated with the ABO locus: the Euro CLOT study. Ann Neurol 2013; 73: 16-31.

8. Iodice S, Maisonneuve P, Botteri E. ABO blood group and cancer. Eur J Cancer 2010; 46: 3345-50.

9. Vasan SK, Hwang J, Rostgaard K, et al. ABO blood group and risk of cancer: A register-based cohort study of 1.6 million blood donors. Cancer Epidemiol 2016; 44: 40-3.

10. Urun $Y$, Utkan G, Cangir AK, et al. Association of $\mathrm{ABO}$ blood group and risk of lung cancer in a multicenter study in Turkey. Asian Pac J Cancer Prev 2013; 14: 2801-3.

11. Alvarez-Fernandez E, Carretero-Albinana L. Expression of blood group antigens by normal bronchopulmonary tissues and common forms of pulmonary carcinomas. Arch Pathol Lab Med 1991; 115: 42-9.

12. Gwin JL, Klein-Szanto AJ, Zhang SY, et al. Loss of blood group antigen A in non-small cell lung cancer. Ann Surg Oncol 1994; 1: 423-7.

13. Sanchez-Mora N, Cebollero PM, Monroy V, et al. Expression of histo-blood group antigens in bronchial squamous metaplasia. Eur Respir J 2007; 29: 268-72.

14. Suadicani P, Hein HO, Gyntelberg F. ABO phenotypes and inflammation-related predictors of lung cancer mortality: the Copenhagen Male Study-a 16-year follow-up. Eur Respir J 2007; 30: 13-20.

15. Rubin H. Fields and field cancerization: the preneoplastic origins of cancer: asymptomatic hyperplastic fields are precursors of neoplasia, and their progression to tumors can be tracked by saturation density in culture. BioEssays 2011; 33: 224-31.

16. Ashley DJB. Blood groups and lung cancer. J Med Genet 1969; 6: 183-6. 